УДК 550.424.4(571.54/.55)

ОСОБЕННОСТИ РАСПРЕДЕЛЕНИЯ И МИГРАЦИИ КОМПОНЕНТОВ

В ВОДАХ МЕСТОРОЖДЕНИЙ ДУРУЛГУЕВСКОГО ГРАНИТОИДНОГО МАССИВА (ВОСТОЧНОЕ ЗАБАЙКАЛЬЕ)

Чечель Л.П., Замана Л.В.

ФГБУН «Институт природных ресурсов, экологии и криологии СО РАН», Чита, e-mail:lpchechel@mail.ru

\begin{abstract}
Изучены параметры миграции компонентов, в том числе редких и редкоземельных элементов, в водах, дренирующих горные выработки и отвалы вскрышных пород Дедовогорского вольфрамового и Ангатуйского оловянного месторождений, расположенных в Восточном Забайкалье. По соотношению основных ионов рассматриваемые воды преимущественно гидрокарбонатные и сульфатно-гидрокарбонатные натриевокальциевые с минерализацией менее 200 мг/л, с околонейтральной и слабокислой реакцией. Максимальные концентрации микрокомпонентов достигают, как правило, единиц-десятков и сотен мкг/л. Выделено два типа ассоциаций химических элементов, характеризующих воды, сформировавшиеся в нарушенных горной отработкой и естественных условиях. Первый тип ассоциаций зафиксирован в водах штольневого стока, карьера и хвостохранилища и представлен $\mathrm{Mn}, \mathrm{Rb}, \mathrm{W}>\mathrm{Li}, \mathrm{F}, \mathrm{Al}, \mathrm{Fe}, \mathrm{Co}, \mathrm{Cu}, \mathrm{Zn}, \mathrm{As}, \mathrm{Mo}, \mathrm{Cd}, \mathrm{Cs}, \mathrm{U}>\mathrm{Sc}$, $\mathrm{Ni}, \mathrm{Ga}, \mathrm{Sr}, \mathrm{Sb}$. Второй тип ассоциаций химических элементов выявлен в водах ручьев за пределами горнодобывающих территорий. Их отличительной чертой является накопление Р3Э и пониженные содержания тяжелых металлов. Этот тип ассоциаций представлен Li, Fe, Rb, W >> F, Al, Sc, Ti, V, Ga, As, Sr, Mo, Sn, Cs, $\sum$ Р3Э, Th. U. Фракционирование редкоземельных элементов, нормализованных по NASC, в водах, формирующихся в естественных и техногенных условиях, также имеет свои особенности. В первом случае их профили имеют очевидное сходство (пологий отрицательный наклон, цериевый и европиевый минимумы); во втором - существенно разнятся (понижение и нарастание значений от легких к тяжелым РЗЭ, отрицательные и положительные аномалии европия).
\end{abstract}

Ключевые слова: месторождения, водная миграция, концентрации компонентов, ассоциации химических элементов, редкоземельные элементы

\title{
PECULIARITIES OF COMPONENTS DISTRIBUTION AND MIGRATION IN WATERS OF DEPOSITS OF DURULGUY GRANITOID MASSIF (EAST TRANSBAIKALIA)
}

Chechel L.P., Zamana L.V.

Institute of Natural Resources, Ecology and Cryology of the Siberian

Branch of the Russian Academy of Sciences, Chita, e-mail: lpchechel@mail.ru

\begin{abstract}
The parameters of the migration of components, including rare earth elements in waters draining mine workings and waste rock dumps of tungsten and tin deposits in the Eastern Transbaikalia are studied. According to the ratio of the main ions, the waters is predominantly bicarbonate and sulphate-bicarbonate sodium-calcium with mineralization of less than $200 \mathrm{mg} / \mathrm{L}$, with near-neutral and weakly acid reaction. The maximum concentrations of microcomponents reach units-tens and hundreds $\mu \mathrm{kg} / \mathrm{L}$. Two types of associations of chemical elements that characterize water formed in mining opening and in the natural conditions are identified. The first type of associations was fixed in the drainage waters of the adit, quarry and tailing and represented $\mathrm{Mn}, \mathrm{Rb}, \mathrm{W} \gg \mathrm{Li}, \mathrm{F}, \mathrm{Al}, \mathrm{Fe}, \mathrm{Co}, \mathrm{Cu}$, $\mathrm{Zn}, \mathrm{As}, \mathrm{Mo}, \mathrm{Cd}, \mathrm{Cs}, \mathrm{U}>\mathrm{Sc}, \mathrm{Ni}, \mathrm{Ga}, \mathrm{Sr}, \mathrm{Sb}$. The second type of associations of chemical elements was found in the waters of streams outside the territories disturbed by mining. Their distinctive feature is the accumulation of REE and low content of heavy metals. This type of associations is represented by $\mathrm{Li}, \mathrm{Fe}, \mathrm{Rb}, \mathrm{W}>>\mathrm{F}, \mathrm{Al}, \mathrm{Sc}, \mathrm{Ti}, \mathrm{V}, \mathrm{Ga}$, As, Sr, Mo, Sn, Cs, $\sum$ REE, Th. U. Fractionation of rare-earth elements in waters formed in natural and disturbed by mining conditions has its own characteristics. In the first case, their profiles have obvious similarities (gentle negative slope, cerium and europium minimums); in the second - significantly different (decrease and increase in values from light to heavy REE, negative and positive anomalies of europium)
\end{abstract}

Keywords: deposits, water migration, concentration of components, chemical elements associations, rare earth elements

Исследование гидрогеохимических полей рудных месторождений Восточного Забайкалья показало, что особенности их формирования в значительной мере определяются геологическим строением и способом отработки месторождений. Состав вмещающих пород, а также наличие либо отсутствие в рудах сульфидной минерализации оказывают решающее влияние на кислотность подземных и поверхностных вод [1; 2], многократно усиливающееся в горнодобывающих регионах. Наибольшую опасность для прилегающих ландшафтов и самой уязвимой их части природных вод представляют отходы добычи и переработки сульфидных руд, в зоне окисления которых формируются кислые сульфатные стоки с аномально высокими концентрациями тяжелых металлов [3-5]. Вместе с тем кажущиеся менее опасными нейтральные и щелочные рудничные дренажи несут ничуть не меньшую угрозу, так как в них 
большую подвижность проявляют высокотоксичные элементы, включающие $\mathrm{As}, \mathrm{Sb}$, Se и др. [5-7].

Цель исследования: изучение условий миграции и накопления компонентов в водах месторождений Дурулгуевской гранитоидной интрузии, выделение типичных для вод района исследований ассоциаций химических элементов.

\section{Материалы и методы исследования}

Изучены распределение и особенности миграции компонентов в водах, дренирующих Дедовогорское вольфрамовое и Ималкинское оловянное месторождения, расположенные в бассейне р. Онон в Восточном Забайкалье (рис. 1). Месторождения приурочены к северному флангу Дурулгуевской гранитоидной интрузии, расположенной в пределах Агинской тектонической зоны и относящейся к кукульбейскому $\left(\mathrm{J}_{3}\right)$ гранит-лейкогранитному комплексу [8;9]. Дурулгуевская интрузия прорывает триасовую толщу зуткулейской свиты слабо метаторфизованных глинистых сланцев, перемежающихся с песчаниками, алевролитами и редкими прослоями конгломератов. К ее северному эндоконтакту приурочено Дедовогорское кварц-вольфрамит-касситеритовое месторождение, на южном фланге массива расположено Ималкинское кварц-касситеритовое месторождение, послужившее источником Ангатуйской россыпи касситерита на его северном фланге.

Участок Дедовогорского месторождения сложен фацией крупнозернистых порфировидных мусковитовых гранитов, сменяющихся на южном фланге биотитовыми порфировидными гранитами. Рудные тела представлены жилами, главные минералы которых - кварц и вольфрамит, второстепенные - гранат и мусковит, редкие - апатит, арсенопирит, касситерит, пирит, халькопирит, сфалерит, борнит. Особое значение в вещественном составе гранитов, грейзенов и кварцевых жил месторождения играют слюды - биотит и мусковит, являющиеся концентраторами редкометалльной минерализации, сопровождаемой редкими щелочами $(\mathrm{Li}, \mathrm{Rb}$, Cs) и фтором. Касситерит на Ималкинском кварц-касситеритовом месторождении встречается в кварцевых, кварцево-полевошпатовых, полевошпатовых и аплитпегматитовых жилах и сопровождается альбитом, микроклином, мусковитом, топазом, флюоритом, вольфрамитом, молибденитом, висмутином, арсенопиритом и другими минералами. Ангатуйская долинная касситеритовая россыпь, источником которой послужило Ималкинское месторождение, сформировалась в пади Большой Ангатуй.

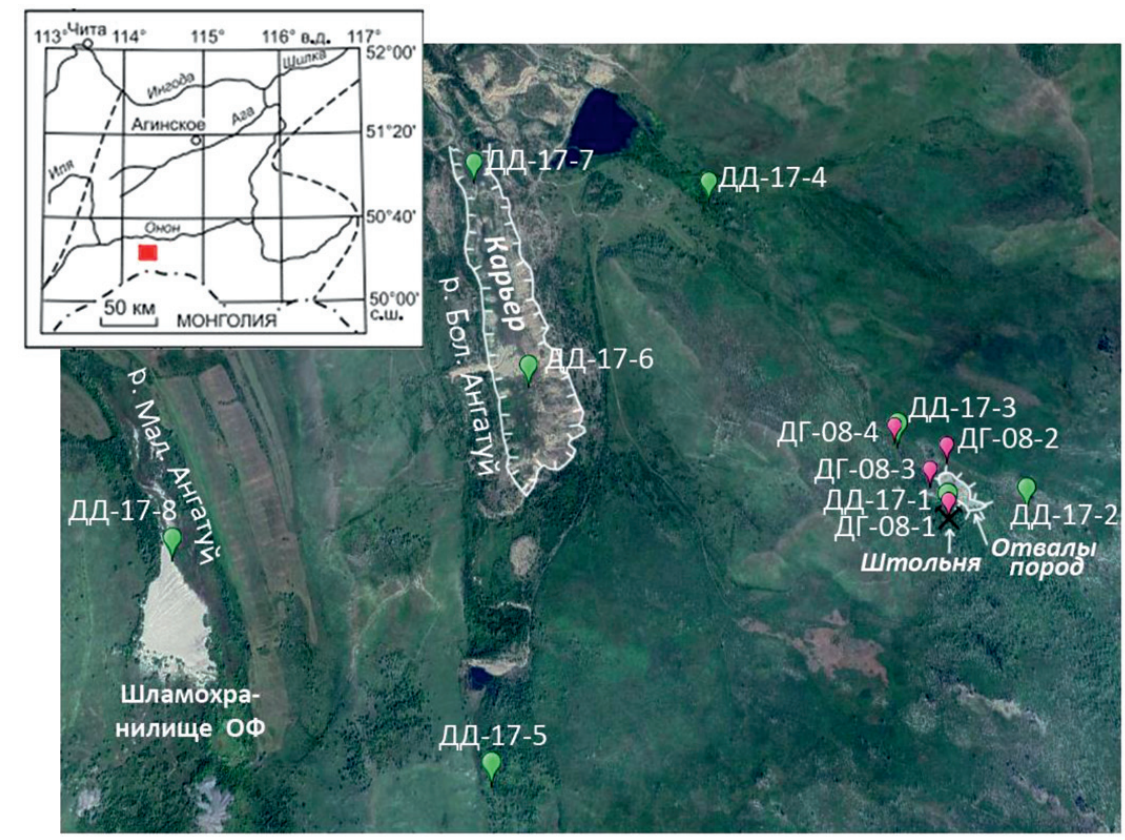

Рис. 1. Местоположение района исследований с нанесением пунктов опробования. На врезке показана территория Агинской зонь (ограничена штриховой линией) [9] 
Дедовогорское месторождение отрабатывалось рудником Ангатуй в 1956-1962 гг. подземным способом, в долине р. Малый Ангатуй в настоящее время расположено хвостохранилище обогатительной фабрики. Разработка Ангатуйской оловянной россыпи осуществлялась карьерным способом вплоть до середины 1990-х гг.

В 2008 и 2017 гг. проведено гидрогеохимическое опробование поверхностных вод на территории разработки Дедовогорского вольфрамового месторождения - были исследованы штольневый дренаж, подотвальный сток и ручей, дренирующий месторождение. Кроме того, в 2017 г. были опробованы ручей в карьере отработки Ангатуйской россыпи и небольшой водоем в нижней части хвостохранилища Дедовогорского месторождения (рис. 1). Было отобрано 12 водных проб, химико-аналитические исследования их проводились общепринятыми методами в Институте природных ресурсов, экологии и криологии СО РАН (г. Чита): турбидиметрией $\left(\mathrm{SO}_{4}^{2-}\right)$, титрованием $\left(\mathrm{HCO}_{3}^{-}\right)$, потенциометрией $\left(\mathrm{Cl}^{-}, \mathrm{F}^{-}\right)$, колориметрией $(\mathrm{Si}$, $\left.\mathrm{P}_{\text {обш }}, \mathrm{NO}_{3}^{-}, \mathrm{NH}_{4}^{+}\right)$. Основные катионы и металлы определялись атомно-адсорбционным методом на спектрофотометре SOLAAR M6. В 2017 г. дополнительно проводился отбор водных проб для их анализа методом
ICP-MS, который выполнялся в Институте геохимии им. А.П. Виноградова СО РАН (г. Иркутск) на приборе высокого разрешения ELEMENT 2 фирмы Finnigan MAT. Для выполнения графических построений были использованы программы Microsoft Excel и OriginPro. Для расчета коэффициентов накопления элементов в водах (Кн) использован кларк речной воды [10].

\section{Результаты исследования и их обсуждение}

Исследованные воды характеризуются гидрокарбонатным, сульфатно-гидрокарбонатным и фторидно-сульфатным анионным составом (рис. 2). По данным опробования 2008 г., существенная его доля принадлежит иону $\mathrm{SO}_{4}^{2-}(28-37 \%$-экв), тогда как в 2017 г. доля сульфат-иона в составе штольневых и подотвальных вод, а также вод ручья, дренирующего Дедовогорское месторождение, заметно ниже (14-20\%-экв). Еще ниже она в водах ручья в карьере отработки Ангатуйской россыпи (4-12\%-экв). Наиболее высока доля иона $\mathrm{SO}_{4}^{2-}$ (44\%-экв) в водах, дренирующих хвостохранилище, в которых вторым по значимости анионом является фторид-ион (40\%-экв). Катионный состав исследованных вод преимущественно $\mathrm{Na}-$ $\mathrm{Ca}$, реже $\mathrm{Mg}-\mathrm{Na}-\mathrm{Ca}$ и $\mathrm{Ca}$.

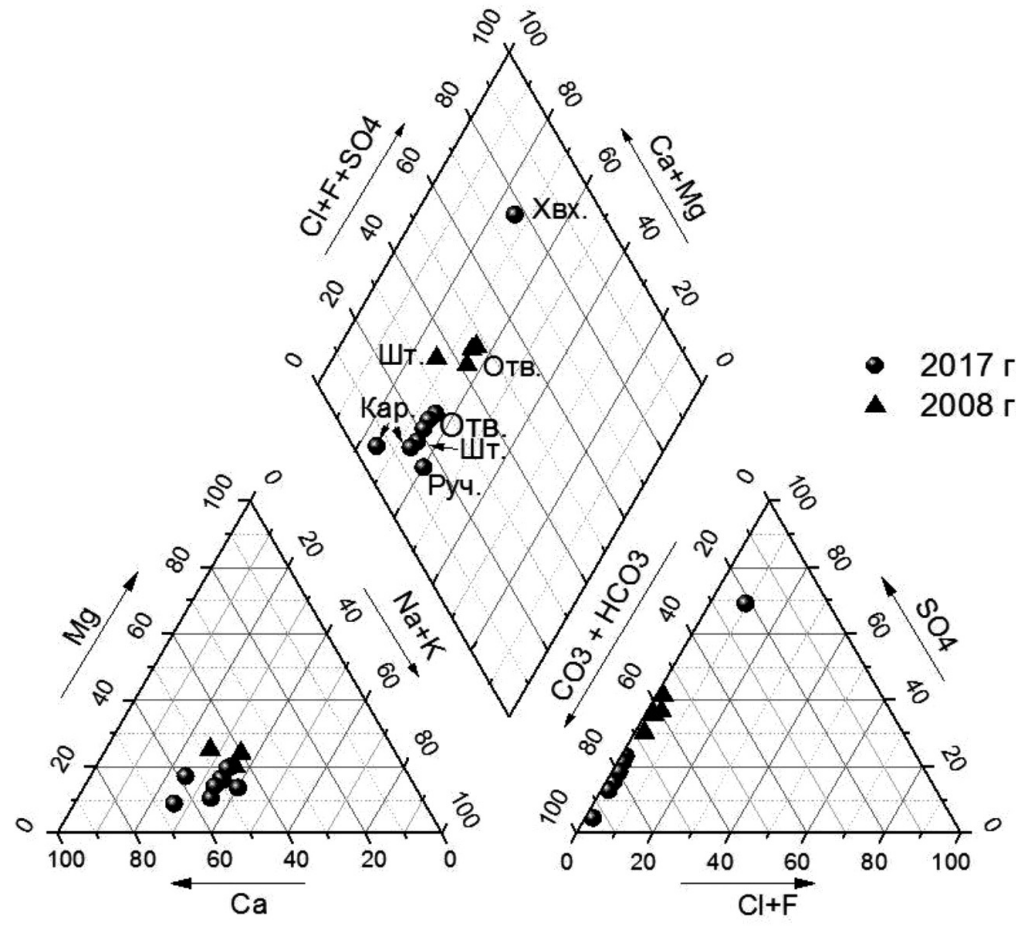

Рис. 2. Диаграмма Пайпера химического состава вод: Хвх. - хвостохранилищза,

Шт. - штольневого стока, Кар. - стока в карьере, Отв. - стока из-под породньх отвалов, Руч. - ручья выше карьера в пади Большой Ангатуй 
Таблица 1

Физико-химические параметры состава вод Дурулгуевского массива

\begin{tabular}{|c|c|c|c|c|c|c|}
\hline Параметр & 1 & 2 & 3 & 4 & 5 & 6 \\
\hline $\mathrm{pH}$ & $\frac{5,98-6,83}{6,41}$ & $\frac{6,71-7,06}{6.91}$ & $\frac{6,15-6,79}{6,55}$ & 6,74 & $\frac{6,25-6,65}{6,45}$ & 5,77 \\
\hline $\mathrm{Eh}, \mathrm{mV}$ & $\frac{218-257}{238}$ & $\frac{239-264}{250}$ & $\frac{239-297}{270}$ & 311 & $\frac{299-303}{301}$ & 348 \\
\hline ПО, мгО/л & $\frac{1,20-1,39}{1,30}$ & $\frac{4,40-7,20}{5,61}$ & $\frac{2,82-6,60}{4,09}$ & 3,54 & $\frac{0,88-1,52}{1,20}$ & 1,12 \\
\hline $\mathrm{CO}_{2}, \mathrm{мг/л}$ & $\frac{1,39-1,76}{1,56}$ & $\frac{0,92-5,28}{2,53}$ & $\frac{0,92-15,4}{6,17}$ & 9,24 & $\frac{5,28-5,72}{5,50}$ & 24,9 \\
\hline $\mathrm{HCO}_{3}^{-}$ & $\frac{35,1-54,9}{45,0}$ & $\frac{14,6-22,0}{21,6}$ & $\frac{17,6-44,5}{34,3}$ & 56,7 & $\frac{64,1-83,6}{73,9}$ & 10,4 \\
\hline $\mathrm{SO}_{4}^{2-}$ & $\frac{8,05-12,5}{10,3}$ & $\frac{6,80-10,7}{8,63}$ & $\frac{7,00-8,90}{8,37}$ & 6,90 & $\frac{3,30-7,70}{5,50}$ & 26,4 \\
\hline $\mathrm{Cl}^{-}$ & $\frac{0,85-1,80}{1,33}$ & $\frac{0,87-2,80}{1,72}$ & $\frac{0,85-1,50}{1,07}$ & 0,87 & $\frac{0,83-0,85}{0,84}$ & 0,75 \\
\hline $\mathrm{F}^{-}$ & $\frac{0,60-1,00}{0,80}$ & $\frac{0,27-0,63}{0,41}$ & $\frac{0,38-0,98}{0,62}$ & 0,59 & $\frac{1,02-1,11}{1,07}$ & 9,31 \\
\hline $\mathrm{Ca}^{2+}$ & $\frac{6,40-9,76}{8,08}$ & $\frac{3,20-5,10}{4,18}$ & $\frac{3,90-7,04}{5,88}$ & 7,66 & $\frac{10,4-15,0}{12,7}$ & 7,34 \\
\hline $\mathrm{Mg}^{2+}$ & $\frac{1,14-2,03}{1,59}$ & $\frac{1,01-1,15}{1,10}$ & $\frac{1,08-1,71}{1,40}$ & 1,37 & $\frac{1,70-2,67}{2,19}$ & 0,6 \\
\hline $\mathrm{Na}^{+}$ & $\frac{4,00-6,59}{5,30}$ & $\frac{3,10-4,00}{3,47}$ & $\frac{3,50-5,30}{4,65}$ & 7,21 & $\frac{7,28-7,33}{7,31}$ & 1,6 \\
\hline $\mathrm{K}^{+}$ & $\frac{0,32-0,82}{0,58}$ & $\frac{0,27-0,74}{0,45}$ & $\frac{0,32-0,83}{0,63}$ & 0,75 & $\frac{0,13-0,70}{0,42}$ & 2,96 \\
\hline $\mathrm{Si}^{+}$ & $\frac{10,0-12,6}{11,3}$ & $\frac{7,60-9,90}{8,64}$ & $\frac{8,10-10,3}{9,53}$ & 16,5 & $\frac{11,3-13,2}{12,3}$ & 0,16 \\
\hline $\mathrm{P}_{\text {обш. }}$ & $\frac{0,08-0,12}{0,10}$ & $\frac{0,083-0,13}{0,099}$ & $\frac{0,083-0,098}{0,090}$ & 0,075 & $\frac{0,075-}{0,090} 0,055$ & 0,088 \\
\hline$\sum$ ионов & $\frac{62,8-83,1}{73,0}$ & $\frac{32,4-46,6}{41,4}$ & $\frac{36,3-69,0}{57,0}$ & 82,0 & $\frac{93,8-113,9}{103,8}$ & 59,4 \\
\hline
\end{tabular}

П р и м е ч а н и е : показаны в числителе - минимальные и максимальные, в знаменателе - средние значения концентраций компонентов; ПО - перманганатная окисляемость; 1 - сток штольни (ДГ-08-1, ДД-17-1); 2 - воды, дренирующие отвал штольни (ДГ-08-2, ДГ-08-3, ДД-17-2); 3 - ручей, дренирующий Дедовогорское месторождение (ДГ-08-4, ДД-17-3, ДД-17-4); 4 - ручей Бол. Ангатуй выше карьера (ДД-17-5); 5 - ручей Бол. Ангатуй в карьере (ДД-17-6, ДД-17-7); 6 - хвостохранилище (ДД-17-8).

По величине щелочно-кислотного показателя рН воды исследованного района в основном околонейтральные и слабокислые (табл. 1). Их минерализация за два периода опробования изменялась в пределах 32,4-113,9 мг/л. Наиболее минерализованные воды зафиксированы в карьере по отработке оловянной россыпи.

Малое количество сульфидов в рудах месторождений, а также достаточно длительный период, прошедший со времени их эксплуатации, явились причиной формирования вод, близких по своим свойствам к фоновым - ультрапресным, нейтральным, преимущественно $\mathrm{HCO}_{3}$-Сa. Миграция многих металлов в нейтральных средах, как известно, ограниченна, и это отражается на их содержаниях в водах. Так, кон- центрации, достигавшие миллиграммовых значений, в рассматриваемых водах свойственны только двум металлам - $\mathrm{Al}$ и $\mathrm{Mn}$. Высоких значений в водах достигают также концентрации железа, цинка, меди, мышьяка и стронция. Максимальные содержания компонентов находятся на уровне единицдесятков, реже сотен мкг/л (табл. 2).

В отличие от них кислым сульфатным водам золоторудных, вольфрамовых и молибденовых месторождений с высоким содержанием в рудах сульфидных минералов свойственны значительно более высокие содержания металлов - до единиц, десятков и сотен мг/л $[3 ; 4 ; 11]$.

Наибольшая техногенная нагрузка на исследуемые воды проявлена на территории, занимаемой хвостохранилищем обо- 
гатительной фабрики Ангатуй. Этим водам свойственны аномальные и повышенные содержания $\mathrm{Al}, \mathrm{Mn}, \mathrm{Fe}, \mathrm{Zn}, \mathrm{Cu}, \mathrm{As}, \mathrm{Sr}, \mathrm{Li}$, $\mathrm{Mo}, \mathrm{Cd}, \mathrm{W}$ (табл. 2). В штольневых водах зафиксированы максимальные для изученных вод концентрации лития, вольфрама и урана. В водах подотвальных дренажей отмечены высокие содержания алюминия, железа, лития, стронция и максимальное суммарное количество редкоземельных элементов (РЗЭ). При прохождении вод ручья через карьер по отработке Ангатуйской оловянной россыпи в них заметно возрастают концентрации железа, мышьяка, стронция и других (табл. 2). Концентрации олова при этом самые низкие.

Таблица 2

Средние содержания микрокомпонентов в водах Дурулгуевского массива

\begin{tabular}{|c|c|c|c|c|c|c|}
\hline Параметр & 1 & 2 & 3 & 4 & 5 & 6 \\
\hline $\mathrm{Li}$ & 75,0 & 18,0 & 29,5 & 52,0 & 56,5 & 32,0 \\
\hline $\mathrm{B}$ & 0,38 & 0,13 & 0,10 & 0,07 & 0,06 & 27,0 \\
\hline $\mathrm{Al}$ & 7,90 & 831,0 & 159,5 & 274,0 & 5,71 & 3264 \\
\hline $\mathrm{Sc}$ & 0,004 & 0,14 & 0,03 & 0,05 & 0,004 & 0,008 \\
\hline $\mathrm{V}$ & 0,14 & 0,96 & 0,39 & 0,85 & 0,12 & 0,01 \\
\hline $\mathrm{Mn}$ & 1,26 & 3,18 & 0,99 & 0,97 & 13,7 & 1116 \\
\hline $\mathrm{Fe}$ & 12,3 & 409,0 & 81,0 & 146,0 & 34,5 & 576,0 \\
\hline $\mathrm{Co}$ & 0,03 & 0,13 & 0,08 & 0,08 & 0,06 & 4,51 \\
\hline $\mathrm{Ni}$ & 0,31 & 1,36 & 0,78 & 1,54 & 0,24 & 9,30 \\
\hline $\mathrm{Cu}$ & 5,40 & 1,97 & 2,76 & 2,25 & 0,72 & 201,0 \\
\hline $\mathrm{Zn}$ & 34,0 & 8,50 & 11,8 & 33,0 & 2,37 & 282,0 \\
\hline $\mathrm{Ga}$ & 0,005 & 0,23 & 0,05 & 0,07 & 0,004 & 0,12 \\
\hline $\mathrm{Ge}$ & 0,02 & 0,02 & 0,009 & 0,01 & 0,006 & 0,03 \\
\hline As & 34,0 & 1,23 & 9,75 & 8,20 & 127,0 & 163,0 \\
\hline $\mathrm{Se}$ & 0,09 & 0,07 & 0,05 & 0,14 & 0,07 & 0,14 \\
\hline $\mathrm{Rb}$ & 2,81 & 1,90 & 0,78 & 0,93 & 0,76 & 5,90 \\
\hline $\mathrm{Sr}$ & 43,0 & 39,0 & 53,0 & 59,0 & 109,0 & 100,0 \\
\hline $\mathrm{Y}$ & 0,04 & 0,39 & 0,18 & 0,22 & 0,02 & 0,05 \\
\hline $\mathrm{Zr}$ & 0,02 & 0,97 & 0,26 & 0,43 & 0,02 & 0,02 \\
\hline $\mathrm{Nb}$ & 0,008 & 0,08 & 0,02 & 0,03 & 0,002 & 0,01 \\
\hline Mo & 2,55 & 0,21 & 0,85 & 1,45 & 1,85 & 20,0 \\
\hline $\mathrm{Ag}$ & 0,03 & 0,01 & 0,013 & 0,01 & 0,003 & 0,11 \\
\hline $\mathrm{Cd}$ & 0,70 & 0,08 & 0,15 & 0,08 & 0,02 & 5,90 \\
\hline $\mathrm{Sn}$ & 0,01 & 0,06 & 0,04 & 0,03 & 0,004 & 0,02 \\
\hline $\mathrm{Sb}$ & 0,44 & 0,17 & 0,16 & 0,18 & 0,17 & 1,27 \\
\hline Cs & 0,28 & 0,19 & 0,05 & 0,06 & 0,05 & 0,62 \\
\hline Hf & 0,0009 & 0,03 & 0,009 & 0,01 & 0,0006 & 0,003 \\
\hline W & 8,00 & 0,09 & 0,42 & 0,23 & 0,51 & 2,36 \\
\hline $\mathrm{Re}$ & 0,0004 & 0,0002 & 0,0001 & 0,0003 & 0,0003 & 0,001 \\
\hline $\mathrm{Pb}$ & 0,004 & 0,13 & 0,05 & 0,06 & 0,005 & 0,02 \\
\hline Th & 0,005 & 0,12 & 0,04 & 0,05 & 0,003 & 0,006 \\
\hline $\mathrm{U}$ & 6,60 & 0,78 & 0,53 & 1,49 & 0,09 & 0,62 \\
\hline$\sum$ Р3Э & 0,11 & 2,24 & 0,97 & 1,29 & 0,09 & 0,26 \\
\hline इЛРЗЭ, \% & 54 & 64 & 64 & 64 & 65,0 & 68 \\
\hline$\sum$ ТРЗЭ,\% & 46 & 36 & 37 & 36 & 35,0 & 32 \\
\hline $\mathrm{La}_{\mathrm{n}} / \mathrm{Yb}_{\mathrm{n}}$ & 0,25 & 0,60 & 0,61 & 0,82 & 1,23 & 1,28 \\
\hline $\mathrm{Eu} / \mathrm{Eu}^{*}$ & 0,68 & 0,88 & 0,81 & 0,91 & 1,52 & 0,64 \\
\hline $\mathrm{Ce} / \mathrm{Ce}^{*}$ & 0,49 & 0,70 & 0,67 & 0,61 & 0,71 & 0,79 \\
\hline $\mathrm{Sm} / \mathrm{Sm}^{*}$ & 1,43 & 1,18 & 1,21 & 1,14 & 0,86 & 1,30 \\
\hline
\end{tabular}

Пр и м еч ан и е : $\sum$ РЗЭ - суммарное количество редкоземельных элементов; $\sum$ ЛРЗЭ - сумма легких, $\sum$ ТРЗЭ - сумма тяжелых РЗЭ; $L a_{n} / Y b_{n}-$ отношение, нормированное NASC; $E u / E u^{*}=2\left(E u_{n}\right) /$ $\left(S m_{n}+G d_{n}\right) ; C e / C e^{*}=2\left(C e_{n}\right) /\left(L a_{n}+P r_{n}\right) ; S^{n} m / S m *=2\left(S m_{n}\right) /\left(P m_{n}+E u_{n}\right)$. 


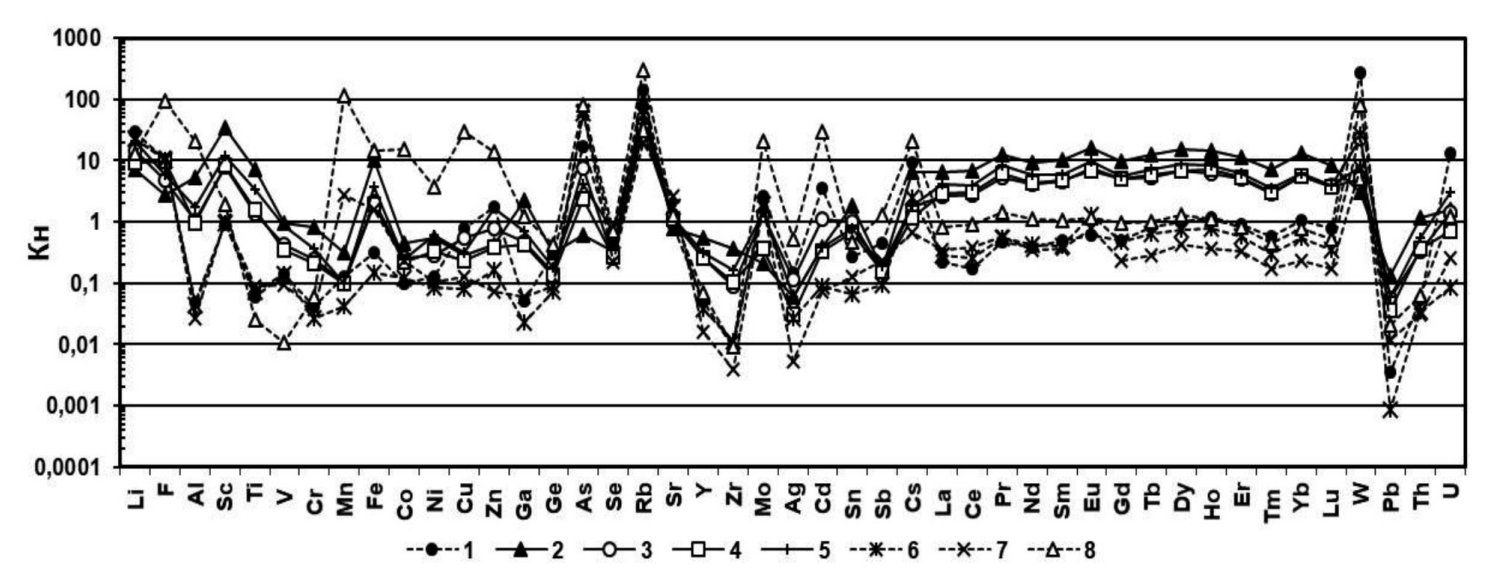

Рис. 3. Спектры распределения элементов, нормированных на кларк речной воды [10], в водах месторождений Дурулгуевского гранитоидного массива. 1 - ДД-17-1, 2 - ДД-17-2, 3 - ДД-17-3, 4 - ДД-17-4, 5 - ДД-17-5, 6 - ДД-17-6, 7 - ДД-17-7, 8 - ДД-17-8

Для оценки техногенного воздействия, а также выделения типичных ассоциаций химических элементов вод гранитоидов Дурулгуевского массива определялся коэффициент накопления (Кн), рассчитанный как частное от деления концентраций элементов на кларк речной воды [10]. Результаты расчетов показаны в виде диаграммы (рис. 3), что позволяет отчетливо видеть два типа распределения элементов.

Первый тип распределения свойственен водам штольневого стока, карьера и хвостохранилища и характеризуется наибольшими значениями Кн $(>100)$ для $\mathrm{Mn}, \mathrm{Rb}$ и $\mathrm{W}$ (рис. 3 - спектры 1,8 ). Также в водах этих объектов (рис. 3 - спектры 1, 6-8) установлены значения коэффициента накопления от 10 до 100 единиц для $\mathrm{Li}, \mathrm{F}, \mathrm{Al}, \mathrm{Fe}, \mathrm{Co}$, $\mathrm{Cu}, \mathrm{Zn}, \mathrm{As}, \mathrm{Mo}, \mathrm{Cd}, \mathrm{Cs}, \mathrm{U}$, от 1 до 10 - для $\mathrm{Sc}, \mathrm{Ni}, \mathrm{Ga}, \mathrm{Sr}$ и $\mathrm{Sb}$. Присутствие в рудных жилах даже малого количества сульфидных минералов служит источником накопления в водах хвостохранилища тяжелых металлов (рис. 3 - спектр 8).

Второй тип распределения присущ водам, дренирующим гранитоиды Дурулгуевского массива - это стоки из-под отвалов пустых пород, а также ручьев в ненарушенных горной отработкой условиях (рис. 3 спектры 2-5). Им свойственно накопление редкоземельных элементов и пониженные содержания тяжелых металлов. Максимальные значения Кн (от 10 до 100 единиц) установлены для $\mathrm{Li}, \mathrm{Fe}, \mathrm{Rb}, \mathrm{W}$, на порядок ниже (от 1 до 10 единиц) - F, Al, Sc, Ti, V, Ga, As, $\mathrm{Sr}, \mathrm{Mo}, \mathrm{Sn}, \mathrm{Cs}, \sum$ РЗЭ, Th и U.

Концентрации редкоземельных элементов в рассматриваемых водах невелики, их суммарные количества достигают первых единиц мкг/л (табл. 2), в отличие от кислых дренажных вод вольфрамовых и молибденовых месторождений, где они, по нашим данным, доходят до 3,6-9,0 мг/л [4; 11].

В целом для рассматриваемых вод характерно преобладание легких лантаноидов над тяжелыми (табл. 2). Нормализованные к NASC значения преимущественно характеризуются обогащением в области тяжелых РЗЭ (табл. 2, рис. 4), что вполне согласуется с литературными данными для нейтральных и слабокислых поверхностных вод [12] и может свидетельствовать о предпочтительной сорбируемости легких лантаноидов $\left(\mathrm{La}_{\mathrm{n}} / \mathrm{Yb}_{\mathrm{n}}=0,25-0,82\right)$. Исключение представляют воды, формирующиеся в карьере отработки Ангатуйской россыпи и в хвостохранилище, которым свойственно обогащение легкими Р3Э - $\mathrm{La}_{\mathrm{n}} / \mathrm{Yb}_{\mathrm{n}}=1,28-$ 1,84 (табл. 2, рис. 4).

Всем спектрам лантаноидов характерны выраженные цериевые минимумы (Ce/ $\left.\mathrm{Ce}^{*}=0,49-0,79\right)$, фиксируемые многими исследователями в нейтральных и щелочных водах и объясняемые удалением его из раствора в результате частичного окисления $\mathrm{Ce}^{3+}$ до малорастворимого $\mathrm{Ce}^{4+}[12]$. Аномалии европия имеют разнонаправленный характер - положительные в водах, дренирующих Ангатуйскую россыпь (Eu/ $\left.\mathrm{Eu}^{*}=1,46-1,58\right)$, и отрицательные в остальных случаях $\left(\mathrm{Eu} / \mathrm{Eu}^{*}=0,64-0,91\right)$. На двух спектрах (рис. 4 - спектры 1 и 8) отмечается самариевый максимум $(\mathrm{Sm} / \mathrm{Sm} *=1,30$ $1,43)$, накопление которого свойственно двуслюдяным гранитам Дурулгуевского массива [13] (рис. 4 - спектр II). 


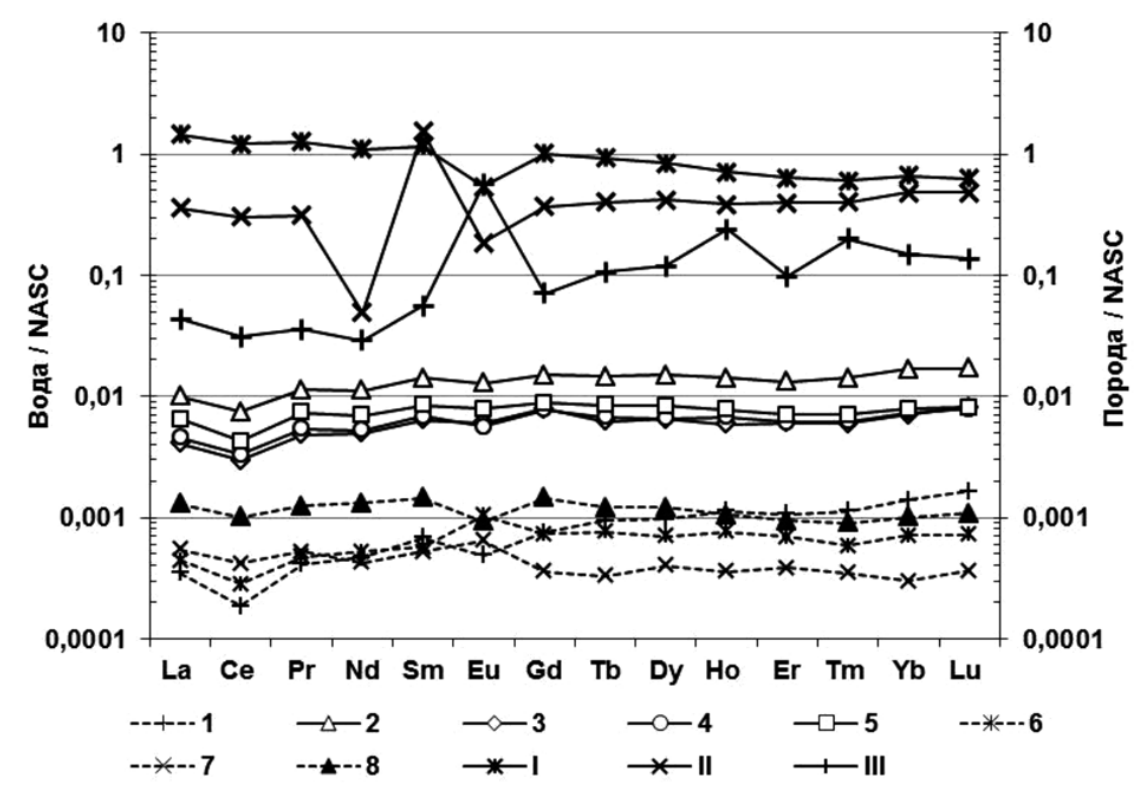

Puc. 4. Спектры распределения нормированных на североамериканский сланеи (NASC) кониентраций РЗЭ в водах (1- ДД-17-1, 2 - ДД-17-2, 3 - ДД-17-3,

4 - ДД-17-4, 5 - ДД-17-5, 6 - ДД-17-6, 7 - ДД-17-7, 8 - ДД-17-8) и гранитах

(I - биотитовых, II - двуслюдяных, III - мусковитовых) Дурулгуевского массива [13]

Конфигурации спектров распределения лантаноидов в водах, дренирующих гранитоиды, имеют очевидное сходство (рис. 4 , спектры - 2-5) - пологий отрицательный наклон $\left(\mathrm{La}_{\mathrm{n}} / \mathrm{Yb}_{\mathrm{n}}=0,58-0,82\right)$, выраженный цериевый и более слабый европиевый минимумы. Одновременно с этим очертания профилей, свойственные водам, формирующимся в нарушенных условиях, отличаются большим разнообразием (рис. 4 , спектры $1,6-8)$. Они имеют как понижение, так и нарастание значений от легких к тяжелым РЗЭ $\left(\mathrm{La}_{\mathrm{n}} / \mathrm{Yb}_{\mathrm{n}}=0,25-1,84\right)$, а также отрицательные для вод штольни и хвостохранилища Дедовогорского месторождения и положительные для вод Ангатуйской россыпи аномалии европия (табл. 2, рис. 4).

При сравнении нормализованных по NASC профилей РЗЭ в воде и в гранитах [13] можно видеть некоторое сходство, но также и расхождения в их фракционировании (рис. 4), что определяется степенью взаимодействия воды с породой и особенностями миграционного поведения химических элементов. Как известно, содержание компонентов в водах есть разница между их количеством, привнесенным в раствор в процессе растворения горных пород, и количеством, осаждаемым в процессе формирования вторичной минеральной фазы, контролируемым ее растворимостью.

\section{Выводы}

В районах разработки Дедовогорского и Ангатуйского месторождений формируются преимущественно ультрапресные, слабокислые и околонейтральные подземные и поверхностные воды гидрокарбонатного и сульфатно-гидрокарбонатного $\mathrm{Na}-\mathrm{Ca}$ и $\mathrm{Mg}$ $\mathrm{Na-Ca}$ состава, за исключением фторидносульфатных кальциевых вод, дренирующих пески хвостохранилища. Максимальные содержания микрокомпонентов достигают единиц-десятков и сотен микрограмм, в редких случаях - единиц миллиграмм в литре. Наибольшая техногенная нагрузка на исследуемые воды зафиксирована на территории, занимаемой хвостохранилищем Дедовогорского месторождения, водам которого свойственны аномальные и повышенные содержания Al, Mn, Fe, Zn, Cu, As, Sr, Li, Mo, Cd, W.

Выделены типичные ассоциации химических элементов в рассматриваемых водах. По степени обогащения вод штольневого стока, карьера и хвостохранилища элементы располагаются в следующем порядке: $\mathrm{Mn}, \mathrm{Rb}, \mathrm{W}>>\mathrm{Li}, \mathrm{F}, \mathrm{Al}, \mathrm{Fe}, \mathrm{Co}, \mathrm{Cu}, \mathrm{Zn}$, As, Mo, Cd, Cs, U >> Sc, Ni, Ga, Sr, Sb. Ocoбенностью вод ручьев в ненарушенных условиях, а также подотвальных вод является накопление РЗЭ и пониженные содержания тяжелых металлов. По степени обогащения 
элементы этих вод располагаются следующим образом: Li, Fe, Rb, W >> F, Al, Sc, Ti, V, Ga, As, Sr, Mo, Sn, Cs, ¿P3Э, Th. U.

Фракционирование редкоземельных элементов, нормализованных по NASC, в водах, формирующихся в естественных и нарушенных горной отработкой условиях, также имеет свои особенности. В первом случае конфигурации спектров их распределения однообразны - имеют пологий отрицательный наклон, отрицательные аномалии Се и Eu; во втором им свойственны заметные расхождения - как понижение, так и нарастание значений от легких к тяжелым РЗЭ, как отрицательные, так и положительные аномалии Еu.

Работа выполнена в рамках проекта IX.137.1. 2. «Геохимия редких и редкоземельных элементов в природных и геотехногенных ландшафтах и гидрогеохимических системах».

\section{Список литературы / References}

1. Бортникова С.Б., Гаськова О.Л., Бессонова Е.П. Геохимия техногенных систем. Новосибирск: Изд-во «Гео», 2006. 169 c

Bortnikova S.B., Gaskova O.L., Bessonova E.P. Geochemistry of technological systems. Novosibirsk: Izd-vo «Geo», 2006. 169 p. (in Russian).

2. Edelev A.V. Composition of drainage mine waters interacting with sulfide-containing rock: a predictive estimation. Russian Geology and Geophysics. 2013. vol. 54. no. 1. P. 100-119. DOI: 10.1016/j.rgg.2012.12.011.

3. Замана Л.В. Геохимия кислых дренажных вод золоторудных месторождений Восточного Забайкалья // Вода: химия и экология. 2013. № 8. С. 92-97.

Zamana L.V. Geochemistry of acidic drainage waters of gold deposits in Eastern Transbaikalia // Water: chemistry and ecology. 2013. № 8. Р. 92-97 (in Russian).

4. Чечель Л.П. Эколого-гидрогеохимические последствия отработки вольфрамовых и молибденовых месторождений Восточного Забайкалья // Известия Томского политехнического университета. Инжиниринг георесурсов. 2017. T. 328. № 6. C. 52-63.

Chechel L.P. Ecological and hydrogeochemical consequences of mining tungsten and molybdenum deposits of Eastern
Transbaikalia // Bulletin of Tomsk Polytechnic University. Geo Assets Engineering. 2017. V. 328. №. 6. P. 52-63 (in Russian).

5. Lindsay M.B.J., Moncur M.C., Bain J.G., Jambor J.L., Ptacek C.J., Blowes D.W. Geochemical and mineralogical aspects of sulfide mine tailings. Applied Geochemistry. 2015. vol. 57. P. 157-177. DOI: 10.1016/j.apgeochem.2015.01.009.

6. Nordstrom D.K., Blowes D.W., Ptacek C.J. Hydrogeochemistry and microbiology of mine drainage: An update. Applied Geochemistry. 2015. vol. 57. P. 3-16. DOI:10.1016/j.apgeochem.2015.02.008.

7. Zhou J., Nyirenda M.T., Xie L., Baolong L., Yue Z., Liu H. Mine waste acidic potential and distribution of antimony and arsenic in waters of the Xikuangshan mine, China. Applied Geochemistry. 2017. vol. 77. P. 52-61. DOI: 10.1016/j. apgeochem.2016.04.010.

8. Гребенников А.М. Дедовогорское вольфрамовое месторождение // Месторождения Забайкалья. М.: Геоинформмарк, 1995. Т. 1. Кн. 1. С. 117-124.

Grebennikov A.M. Dedovogorskoe tungsten deposit// Transbaikalia deposits. M :: Geoinformmark, 1995. Vol. 1. B. 1. P. 117-124 (in Russian).

9. Kozlov V.D. Trace-element composition and origin of granitoids from the Shakhtama complex and Kukul'bei raremetal complex (Aga zone, Transbaikalia). Russian Geology and Geophysics. 2011. vol. 52. no. 5. P. 526-536. DOI: 10.1016/j. rgg.2011.04.005.

10. Соловов А.П., Архипов А.Я., Бугров В.А. Справочник по геохимическим поискам полезных ископаемых. М.: Недра, 1990. 335 с

Solovov A.P., Arkhipov A.Y., Bugrov V.A. Reference book on geochemical prospecting of minerals. M.: Nedra, 1990. 335 p. (in Russian).

11. Чечель Л.П. Редкие металлы в техногенно-трансформированных водах Жирекенского, Шахтаминского и Бугдаинского молибденовых месторождений (Восточное Забайкалье) / Международный научно-исследовательский журнал. 2018. № 10-1 (76). C. 110-114. DOI: 10.23670 / IRJ.2018.76.10.024

Chechel L.P. Rare metals in technogenically transformed waters of Zhireken, Shakhtaminsky and Bugdainsky molybdenum deposits (Eastern Transbaikalia) / International scientific and research journal. 2018. № 10-1 (76). P. 110-114 (in Russian).

12. Chudaeva V.A., Chudayev O.V. Accumulation and Fractionation of Rare Earth Elements in Surface Waters of the Russian Far East under the Conditions of Natural and Anthropogenic Anomalies. 2011. Geochemistry Int. Vol. 49. no. 5. P. 498-524. DOI: 10.1134/S0016702911030049.

13. Zagorsky V.E. The Durulgui rare-metal granite-pegmatite system in the eastern Transbaikal region: Petrological and geochronological aspects. Doklady Earth Sciences. 2016. vol. 471. no. 1. P. 1134-1139. DOI: 10.1134/S1028334X1611026X. 